\title{
Screening and identification of novel cellulolytic Trichoderma species from Egyptian habitats
}

\author{
Omar A. Hewedy *, A. M. El-Zanaty, A. I. Fahmi \\ Department of Genetics, Faculty of Agriculture, Menoufia University, Shibin, El-Kom, Egypt
}

\begin{abstract}
The present study aimed to isolate indigenous Trichoderma fungi possessing cellulolytic activities from different geographical locations in Egypt. Such strains can be used to convert crop residues to bioproducts, which presently is one of the most important issues in developing countries. The isolates were identified using molecular approaches and morphological characteristics. Favorable growth conditions for Trichoderma isolates (media \& temperature) were assessed in vitro. The growth rate of Trichoderma isolates was assessed on two media, namely Potato Dextrose Agar (PDA) and Synthetic Nutrient Agar (SNA), and morphological parameters, i.e., shape, pigment, and edge were observed. A comparison of sequences encoding for internal transcribed spacer (ITS) and translation elongation factor $1-\alpha$ (tef1) was conducted to determine the species. Cellulase assay was performed using different cellulose substrates (Swollen, CMC (low viscosity carboxymethylcellulose), and Avicel). Among the isolated fungi, Trichoderma viride EGY-T27 had the highest endoglucanase activity, while Trichoderma harzianum EGY-T30 showed the highest exoglucanase activity. A total of 27 strains of Trichoderma were identified using ITS, and the tef1 gene was sequenced for 23 strains. The tested strains were identified with acceptable quality based on ITS sequences, which ranged from 98 to 100\%, except for strain MH908499 (85\%). This research constitutes the most comprehensive study on screening for fungal strains with the highest biodegradable potential isolated from various locations in Egypt.
\end{abstract}

Key words: Trichoderma, cellulase activity, biodegradation, ITS, tef1

\section{Introduction}

Trichoderma species are well known for their ability to colonize different substrates and diverse environmental habitats. They inhabit the rhizosphere layer of the soil with a rapidly growing rate, producing a large number of spores and degrading enzymes for their nutrition. Additionally, Trichoderma fungi are considered to be one of the most widely distributed fungi in nature and can grow in a wide range of climates (Seidl, 2006; Topolovec-Pintarić, 2019). Some Trichoderma strains are endophytes that promote plant health and serve as biocontrol agents via mycoparasitism; they are also used as biopesticides instead of synthetic pesticides and as biofertilizers for enhancing root development (Arnold et al., 2003; Benítez et al., 2004; Harman et al., 2004; Barari, 2016). Trichoderma can also grow on various substrates such as wood, soil, crop residues, and some plant habitat niches as endophytes (Samuels et al., 2006; Bailey and Melnick, 2013; Chaverri and Samuels, 2013). They are currently widely used in industrial applications because of their ability to produce extracellular hydrolases in large amounts (Mach and Zeilinger, 2003; Samuels et al., 2006). Their ability to produce numerous digestive enzymes such as cellulose, hemicellulose, lignin, and chitin that break down various biopolymers have been utilized as a strategy for degrading various agricultural wastes and biomass, with biofuel as the most valuable product of this hydrolysis process (Druzhinina et al., 2018c). The development of alternative energy strategies is a critical factor because of the rising prices of crude oil as well as for reducing environmental pollution. Therefore, bioconversion of lignocellulosic residues

\footnotetext{
* Corresponding author: Department of Genetics, Faculty of Agriculture, Menoufia University, Shibin, El-Kom, Egypt; e-mail: hewedy.omar@gmail.com
} 
is initiated primarily by microorganisms such as Trichoderma reesei and Aspergillus niger. T. reesei is a Trichoderma species that is commercially used for the production of cellulolytic enzymes required for making biofuels and is also used in other industries (Dashtban et al., 2009; Druzhinina et al., 2018c).

Cellulose and hemicellulose polysaccharides are $\beta$-(1,4)-linked glucose polymers with diverse compositions. Evidently, they constitute $60-80 \%$ of the plant cell wall. This lignocellulosic biomass, which includes forest wastes and residues of crops, is considered the world's most abundant natural biopolymer and renewable resource on the Earth (Singhania et al., 2013). It is a promising sustainable source of substrate in the production of bioethanol (Gusakov, 2013). Nevertheless, the high price of cellulase extraction and processing increases the cost of biofuel production compared to that of fossil fuels, which limits the commercial production of biofuel on a large scale (Wu et al., 2011). A promising strategy for efficient utilization of renewable resources is the hydrolysis of lignocellulosic biomass by filamentous fungi such as Trichoderma. Cellulase enzymes comprise a mixture of three major enzyme classes: endoglucanase (EC 3.2.1.4) that attack multiple internal sites in the regions of the cellulose fiber, cellobiohydrolase (EC 3.2.1.91), and glucosidase (EC 3.2.1.21) (El-Zawahry et al., 2010; Adsul et al., 2019). These enzymes are used not only in the biodegradation of wastes, but they also have extensive applications in animal feed; textiles; grain alcohol fermentation; pulp and paper processing; starch processing; and pharmaceutical, malting, and food industries (GordilloFuenzalida et al., 2019; Zhanga et al., 2019). Trichoderma can produce high yields of endo/ exoglucanases, but its low yield of $\beta$-glucosidase has diminished its industrial value (Dashtban and Qin, 2012; Tiwari et al., 2013; de Souza et al., 2018). By using a series of chromatographic procedures, four endoglucanases (Endo I, II, III, and IV) and one exoglucanase (Exo II) were isolated from a commercial cellulase preparation derived from $T$. viride (Kim et al., 1994). Additionally, T. reesei is considered as one of the most industrially useful Trichoderma species for cellulase processing (Mandels and Reese, 1957; Gomes et al., 1992; Keshavarz and Khalesi, 2016; Druzhinina and Kubicek, 2017b).

Glucose is the most abundant monosaccharide produced in plant tissues and most algae during photosynthesis. Therefore, the conversion of cellulosic and hemi- cellulosic polymers into bioethanol via glucose or platform chemicals is considered as an important alternative method to reduce carbon dioxide emission and reduce the overdependence on fossil fuels (Schuster et al., 2012). The traditional methods used for eliminating cellulolytic materials and biological wastes have a negative influence on the environment and climate. Moreover, global energy demand is increasing with the rapidly growing human population, and recently, the rapid consumption of fossil fuels, for instance, has resulted in its depletion, which has raised questions concerning environment safety. Lignocellulosic biomass has emerged as an alternative solution for these issues because of the high cost of cellulase preparation and difficult fermentation process and to reduce the destructive effect on environment due to the burning of rice straw for instance. It is therefore necessary to enhance the hydrolytic efficiency of promising strains such as Trichoderma for lignocellulosic biomass.

The present study evaluated the diversity of Trichoderma isolates in several Egyptian locations. Thus, the present work focused on the identification of representative Egyptian Trichoderma isolates, determination of their favorable growth conditions, and screening of the cellulase activity of fungi from native environmental sources at different geographical locations to select the promising isolates of cellulase production.

\section{Materials and methods}

\section{Fungal isolates and collection sources}

A library of 40 Trichoderma isolates was randomly collected from the rhizosphere soil samples associated with various crop residues located at 38 different geographic habitats in Egypt (Table 1, Fig. 1). Each sample contained $200 \mathrm{~g}$ of soil collected from a depth of approximately $20 \mathrm{~cm}$. The samples were placed in sterile polyethylene bags, transported to the laboratory, and stored at $4{ }^{\circ} \mathrm{C}$ until isolation according to the method of Elad et al. (1981). Briefly, approximately $10 \mathrm{~g}$ of each homogeneous soil sample was weighed and transferred to a $250 \mathrm{ml}$ Erlenmeyer flask containing $100 \mathrm{ml}$ of sterile water and shaken at $150 \mathrm{rpm}$ for $2 \mathrm{~h}$ to make the stock solution. Subsequently, a series of 10 -fold dilutions of the suspension were prepared for each sample, and $100 \mu \mathrm{l}$ of each dilution was plated on Potato Dextrose Agar (PDA). The isolates of Trichoderma spp. were sub- 
Table 1. Different crop residues for Trichoderma isolation collected from different geographical locations

\begin{tabular}{|c|c|c|c|c|c|}
\hline Isolate code & Habitats & Crop residues & Soil type & $\begin{array}{l}\text { No. of location(s) } \\
\text { surveyed }\end{array}$ & $\begin{array}{c}\text { No. of Trichoderma } \\
\text { isolates }\end{array}$ \\
\hline EGY-T1 & Quwesna & corn & Peat & 3 & 3 \\
\hline EGY-T2 & Banha & rice straw & Clay Loam & 4 & 4 \\
\hline EGY-T3 & Berket-Elsaba & berssem & Loamy & 2 & 1 \\
\hline EGY-T4 & Tanta & rice straw & Clay Loam & 3 & 1 \\
\hline EGY-T5 & Kafer-Elshikh & rice straw & Clay Loam & 3 & 1 \\
\hline EGY-T6 & Behra & tomato & Loamy & 5 & 1 \\
\hline EGY-T7 & Alexandria & rice straw & Clay & 1 & 1 \\
\hline EGY-T8 & Menia & tomato & Loamy & 3 & 1 \\
\hline EGY-T9 & Cairo & grape & Sandy - Clay & 3 & 0 \\
\hline EGY-T10 & Alarish & olive & Calcareous & 1 & 0 \\
\hline EGY-T11 & North-Sinai & pomegranate & Calcareous & 1 & 1 \\
\hline EGY-T12 & Elein- Elsokhna & pomegranate & Sandy & 2 & 1 \\
\hline EGY-T13 & Suiez & citrus & Chalk & 3 & 1 \\
\hline EGY-T14 & Assiut & sugar cane & Silt & 2 & 1 \\
\hline EGY-T15 & Sallum & barley & Calcareous & 1 & 0 \\
\hline EGY-T16 & Giza & eggplant & Sandy - Clay & 1 & 0 \\
\hline EGY-T17 & Fayum & cotton waste & Clay Loam & 3 & 1 \\
\hline EGY-T18 & Helwan & corn & Sandy & 4 & 1 \\
\hline EGY-T19 & Giza & tomato & Sandy - Clay & 2 & 0 \\
\hline EGY-T20 & Santkatrein & olive & Calcareous & 4 & 2 \\
\hline EGY-T21 & Damietta & rice straw & Loamy & 3 & 1 \\
\hline EGY-T22 & Zagazig & wheat & Clay Loam & 3 & 0 \\
\hline EGY-T23 & Sadat & grape & Limestone saline & 4 & 1 \\
\hline EGY-T24 & Zefta & cotton waste & Sandy - Clay & 3 & 3 \\
\hline EGY-T25 & Fayed & citrus & Sandy & 4 & 2 \\
\hline EGY-T26 & Dakahlia & rice straw & Clay Loam & 2 & 0 \\
\hline EGY-T27 & Rafah & olive & Calcareous & 2 & 1 \\
\hline EGY-T28 & Beni Suef & onion & Calcareous & 3 & 1 \\
\hline EGY-T29 & Taba & cantaloupe & Sandy & 1 & 0 \\
\hline EGY-T30 & Sohag & onion & Sandy & 3 & 1 \\
\hline EGY-T31 & Mansoura & rice straw & Loamy & 3 & 2 \\
\hline EGY-T32 & New Valley & onion & Loamy & 2 & 0 \\
\hline EGY-T33 & Assiut & cotton waste & Clay & 2 & 0 \\
\hline EGY-T34 & Ismailia & corn & Sandy & 3 & 0 \\
\hline EGY-T35 & New Nubariya & mango & Sandy - Clay & 3 & 0 \\
\hline EGY-T36 & Luxor & peach & Sandy - Clay & 3 & 2 \\
\hline EGY-T37 & Beni Suef & olive & Sandy & 1 & 0 \\
\hline EGY-T38 & Qena & onion & Sandy - Clay & 2 & 1 \\
\hline EGY-T39 & Aswan & barley & Clay Loam & 2 & 0 \\
\hline EGY-T40 & South Sinai & bean & Calcareous & 2 & 2 \\
\hline
\end{tabular}




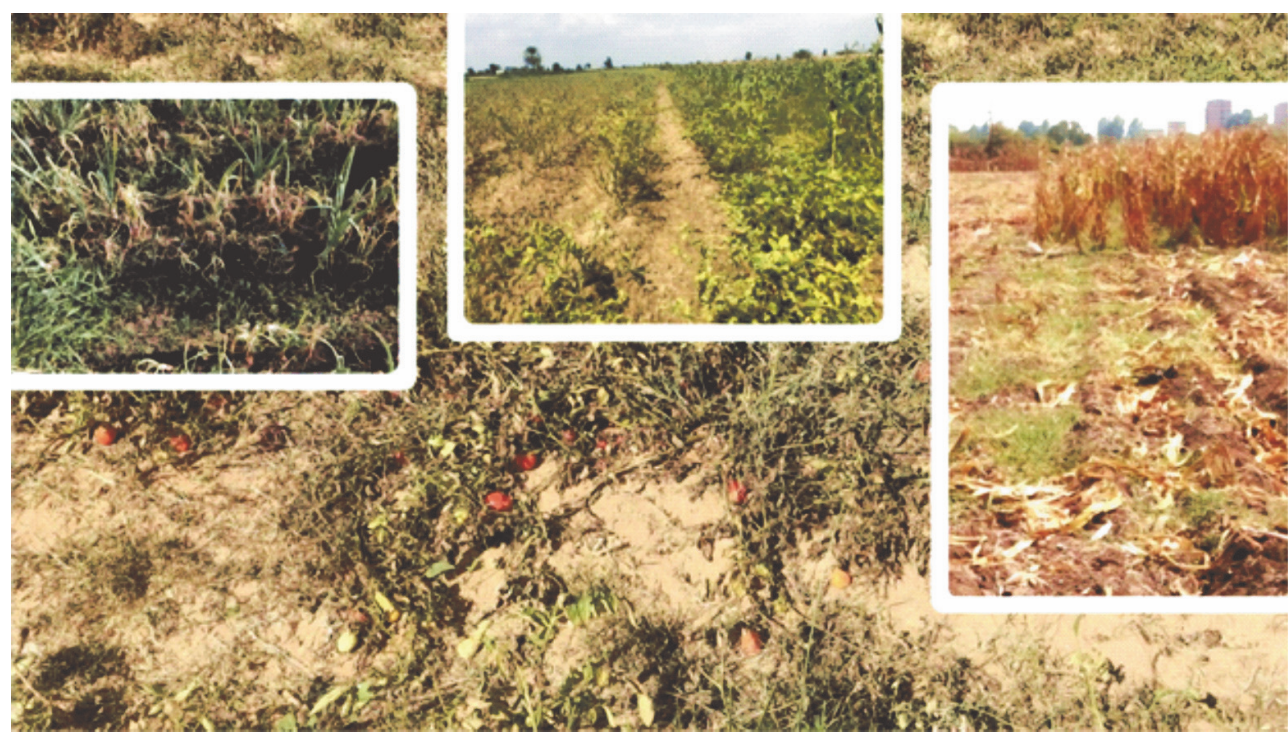

Fig. 1. Examples of different crop residues from different geographical locations used for Trichoderma isolation

cultured and purified by the spread plating technique to obtain monosporic cultures (Rodrigues et al., 2014). All the studied isolates were cultured on PDA containing $200 \mathrm{~g}$ potato infusion, $20 \mathrm{~g}$ dextrose, and $20 \mathrm{~g}$ agar (per/l) supplemented with streptomycin sulfate $(0.4 \mathrm{mg} / \mathrm{ml})$ in $9 \mathrm{~cm}$ Petri plates and incubated at $28^{\circ} \mathrm{C}$ for $5-7$ days. Trichoderma cultures were maintained on PDA slants and stored in $50 \%$ glycerol stocks at $-20^{\circ} \mathrm{C}$ for future studies.

\section{Morphological characterization of Trichoderma spp.}

Trichoderma spp. were identified on the basis of their morphological and cultural characteristics, which included several morphological parameters such as colony shape, color, and edge and the growth rate of Trichodermafungi on different culture media. Growth rates of pure Trichoderma cultures and the optimum temperature for growth were determined on two different media, namely Potato Dextrose Agar (PDA) following the protocol of Samuels et al. (2002) and Synthetic Nutrient Agar (SNA) according to Nirenberg (1976), in $9 \mathrm{~cm}$ Petri plates at $25^{\circ} \mathrm{C}$ and $30^{\circ} \mathrm{C}$. The colony radius was measured each day during the incubation period at intervals of $24 \mathrm{~h}$ until $120 \mathrm{~h}$ at $25^{\circ} \mathrm{C}$ and $30^{\circ} \mathrm{C}$, with $12 \mathrm{~h}$ light and $12 \mathrm{~h}$ darkness. To prepare inoculum, the cultures were incubated at $28^{\circ} \mathrm{C}$ for 5 days on PDA, and the inoculum was placed at $5-10 \mathrm{~mm}$ distance from the edge of the plate by using an agar disc ( $5 \mathrm{~mm}$ diameter) with a fiveday-old Trichoderma mycelium. Additional characteris- tics of Trichoderma colonies were noted, including growth rate, the shape of colonies, colony edge, and the occurrence of pigment diffusion in the agar. The color of each isolate was noted by inverting Petri dishes to observe the different diffusing pigments between the isolates. Each growth rate experiment was repeated three times, and the results were averaged for each isolate.

\section{Molecular characterization of Trichoderma spp.}

\section{DNA Extraction and PCR Amplification}

Genomic DNA was isolated from the cultivated fungal mycelium in $20 \mathrm{ml}$ of Potato Dextrose Broth (PDB) at $28^{\circ} \mathrm{C}$ on a rotary shaker $(200 \mathrm{rpm})$ for 5 days. The mycelium was harvested by filtration through mesh sieves $(40 \mu \mathrm{m})$, washed with sterile water, and deposited on a Whatman filter paper (Sigma-Aldrich, India) to remove excess water. The mycelium was then ground to a fine powder in liquid nitrogen by using a sterilized mortar, and DNA was extracted according to the manufacturer's instructions by using Norgen's Plant/Fungi DNA Isolation Kit (Norgen Biotek Corp., Canada) with some modifications of the protocol by (Dodd et al., 2002; Chi et al., 2009).

The DNA samples were purified using the spin column method of the DNA isolation kit and stored at $-20^{\circ} \mathrm{C}$ for PCR amplification. The quality of DNA was assessed in 1\% agarose gel, which was run in an horizontal electrophoresis unit (Bio-Rad, USA) at $100 \mathrm{~V}$ for 
$30 \mathrm{~min}$. The image of DNA was captured by the E-Gel ${ }^{\mathrm{TM}}$ Imager System with E-Gel ${ }^{\mathrm{TM}}$ Adaptor. The sequences of fungal internal transcribed spacer (5.8SITS) amplified using a pair of general primers ITS4 $\left(5^{\prime}-\right.$ TCCTCCGCT TATTGATATGC $-3^{\prime}$ ) and ITS5 (5'-GGAAGTAAAAGT CGTAACAAGG-3') (Eurofins) as described by (Möller et al., 1992; Schoch et al., 2012; Montoya et al., 2016). The other amplified gene coded for transcription elongation factor 1- $\alpha$ (tef1). PCR amplification was performed using the tef1 primers (Eurofins): EF1-728F: (5' - CATC GAGAAGTTCGAGAAGG- $3^{\prime}$ ) and TEF1R: ( $5^{\prime}$-GCCATC CTTGGAGATACCAGC- $3^{\prime}$ ) as reported by (Samuels et al., 2002). PCR amplification of the ITS and tef1 was performed in a total volume of $20 \mu \mathrm{l}$ reaction mixture containing $0.5 \mu \mathrm{l}$ of each primer $(10 \mathrm{pmol} / \mu \mathrm{l}), 1.0 \mu \mathrm{l}$ of genomic DNA (10 ng/ $\mu \mathrm{l}), 10 \mu \mathrm{l}$ of $2 \times$ PCR MasterMix buffer (Thermo Fisher Scientific Biosciences GmbH, Germany; $0.05 \mu \mathrm{g} / \mu \mathrm{l}$ Taq polymerase, $4 \mathrm{mM} \mathrm{MgCl}_{2}$, and $0.4 \mathrm{mM} \mathrm{dNTPs}$ ), and $8 \mu \mathrm{l}$ of ultrapure sterile water using Thermal Cycler (BIO-RAD) according to (Montoya et al., 2016). After amplification, the PCR fragments were electrophoresed on $2 \%$ agarose gel with a $100 \mathrm{bp}$ DNA ladder (MBI Fermentas) at $80 \mathrm{~V}$ for $20 \mathrm{~min}$, stained with $0.5 \mu \mathrm{g} / \mathrm{ml}$ ethidium bromide water solution for $15 \mathrm{~min}$, and examined by a gel imaging system (Bio-Rad, Gel Doc).

\section{DNA Barcoding and phylogenetic analysis}

PCR products were purified using the QIAquick PCR Purification Kit (Qiagen, USA). The purified PCR products were subjected to Sanger sequencing in binary directions with the BigDye terminator v3.1 sequencing kit and a 3730XL automated sequencer (Applied Biosystems, Foster City, CA) by using ITS4 and ITS5 to ensure the identification of Trichoderma isolates. Nucleotide sequences were determined on both strands of PCR amplification products at the Macrogen sequencing facility (Macrogen Inc., Seoul, Korea). The nucleotide sequences were assembled using Sequencer ABI PRISM 3730XL Analyzer. FASTA sequence alignments were conducted with BLASTN programs and compared with the reference sequences deposited in the NCBI GenBank database. Phylogenetic tree affiliations were generated by a Neighbor-Joining method using MEGA version 7.0 (Kumar et al., 2016). The 5.8S-ITS sequences were compared to a specific database for Trichoderma by using the TrichOKEY2 program http://www.isth.info/
(Druzhinina et al., 2005a). The GenBank accession numbers for the sequences included in the analysis are listed in Table 3. Phylogenetic data were obtained by aligning the nucleotides of both ITS rDNA and tef1 retrieved from the BLAST algorithm (Fig. 3).

\section{Evaluation of the potential of Trichoderma isolates to produce cellulases}

The collection of 40 Trichoderma isolates was screened for their ability to produce cellulase and to determine cellulase activity by using different substrates such as Swollen, Avicel, and carboxymethyl cellulose (CMC) following a protocol by Fahmi et al. (2016). The experiments were performed in triplicate for statistical analysis.

\section{Statistical analysis}

All statistical analyses were performed by one-way analysis of variance (ANOVA) using IBM SPSS Statistics v25.0 HF001 IF007 software.

\section{Results}

\section{Habitat and distribution}

Forty fungal isolates were collected from soil samples associated with 20 types of crop residues, including corn, tomato, wheat, grape, olive, and onion, from 38 geographic habitats in Egypt as shown in Table 1 and Figure 1. The cultures of each isolate were maintained for further experimentation. Five replicates were obtained from each geographic site as a representative of various Egyptian locations to study the biodiversity of the isolated fungi based on the cultivated crop and climatic conditions.

\section{Sample collection and Trichoderma isolation}

Egypt's agricultural production, food security, and environmental conservation depend on the country's remarkable biodiversity. Egypt's agrobiodiversity encompasses not just its wide variety of species and genetic resources but also the numerous practices that farmers employ to use, enhance, and conserve this diversity (Lloyd, 2017). Rhizosphere soil samples were screened for Trichoderma genera with the highest cellulase activities. Forty Trichoderma isolates were successfully isolated from the rhizosphere soil layer of 19 different crop residues (Table 1). The samples of different rhizosphere soils were examined to determine the soil type of each 
location at the Soil, Water and Environment Research Institute in Egypt, which are summarized in 10 soil types as shown in Table 1.

\section{Temperature effect on the growth rate of Trichoderma isolates in vitro}

The growth rates of Trichoderma isolates were measured after $1,2,3,4$, and 5 days at two different temperatures $\left(25^{\circ} \mathrm{C}\right.$ and $\left.30^{\circ} \mathrm{C}\right)$ while inoculated on two different growth media (PDA and SNA). The results (Table 2, Fig. 2) showed a significant variation in the culture growth depending on the type of media used and incubation temperature. Significant differences were observed in a community of Trichoderma species from soils with different crop types. Additionally, the sporulation patterns of the isolated Trichoderma species were affected by media type and temperature. The growth rates varied notably between the studied isolates, for instance, Trichoderma EGY-T3 from loamy soil and berssem residues showed the highest growth rate of 6.36 and $6.10 \mathrm{~cm}$ after 5 days of incubation on PDA media at $25^{\circ} \mathrm{C}$ and $30^{\circ} \mathrm{C}$, respectively. Trichoderma isolates EGY-T10 and EGY-T15 had the highest growth rate ranging between 4.26 and $4.10 \mathrm{~cm}$ on PDA and SNA media at $25^{\circ} \mathrm{C}$ and $30^{\circ} \mathrm{C}$, respectively. On the other hand, the isolated fungal strains EGY-T40 and EGY-T32 from South Sinai and New Valley had the lowest growth rates (3.38 and $3.90 \mathrm{~cm}$, respectively) at $25^{\circ} \mathrm{C}$ and $30^{\circ} \mathrm{C}$ on PDA. These isolates were collected from bean and onion residues from calcareous and loamy soils. The inoculation of Trichoderma EGY-T12 and EGY-T10 isolates on SNA at $25^{\circ} \mathrm{C}$ and $30^{\circ} \mathrm{C}$ showed the lowest growth rates of 2.08 and $1.24 \mathrm{~cm}$, respectively, after 5 days from inoculation. These results indicate that the fungal strain, nutrient source, and temperature influence the growth rates of the studied Trichoderma isolates (Fig. 2A, 2B and $2 \mathrm{C}$ ). The second parameter used for morphological observations was the color of the backside of Petri dishes, which is a morphological characteristic to differentiate the studied isolates (Fig. 2D). Although the morphological identification clearly indicated that the fungal isolates were Trichoderma, its ability to classify them into species was not quite precise. Therefore, molecular identification was used as a second method to clearly classify the fungal isolates.

\section{DNA sequencing and phylogenetic analysis of ITS and tef1 genes}

To identify Trichoderma species, several molecular methods were conducted. The sequences of ITS and tef 1 genes were sequenced to identify the strains and study the biodiversity relationship between them. The sequences of the ITS fragments (ITS4-ITS5) were analyzed using the nucleotide BLASTN program. The National Center for Biotechnology Information (NCBI) database was used to assess the similarity by comparing to homologous sequences deposited in NCBI GenBank https:// www.ncbi.nlm.nih.gov/nuccore.

One band of $620 \mathrm{bp}$ was amplified using ITS primers, and one band of $610 \mathrm{bp}$ was obtained in the amplification of the tef1 gene. Purified PCR products were sequenced, and the data were compared with the published ITS data on NCBI by using BLASTn analysis. The identified Trichoderma species are summarized in Table 3 along with their corresponding NCBI accession numbers (MH908491-MH908517). A total of 7 strains of $T$. harzianum Clade, 7 strains of $T$. afroharzianum Clade, 5 strains of $T$. asperellum Clade, 3 new species, and one of each taxa with T. asperelloides, T. aureoviride, T. longibrachiatum, T. viride, and $T$. atrobrunneum strains were detected. ITS sequences provide poor resolution for differentiation of closely related species (Case et al., 2007); moreover, the phylogenetic analysis positioned three unknown species in Trichoderma fungi. Hence, for more detailed determination of fungal species, the amplification of tef 1 was used for comparing both similarities and differences between the isolates to confirm that the identified species was Trichoderma. In addition, there are varying relative frequencies of occurrence of isolates in the different locations with different crop residues in soils associated with different crop cultivation. Interestingly, the most relative frequency of occurrence of the isolates was $T$. harzianum under different seasonal crops such as tomato, onion, and rice crops in loamy soils. Furthermore, T. harzianumfrom loamy soils was more common than that in sandy soils. Furthermore, only $T$. viride was isolated from olive crop residues in calcareous soils, while $T$. atrobrunneum and $T$. asperelloides were isolated from bean and corn residues, respectively. The distribution of four nucleotides (ATGC) and the length of the ITS region of the identified strains are given in Table 4 . 
Table 2. Colony characteristics of different Trichoderma isolates grown on PDA after seven days of incubation in dark at $28^{\circ} \mathrm{C}$ and the average of growth rate per day cultured on PDA and SNA in dark for five days at $25^{\circ} \mathrm{C}$ and $30^{\circ} \mathrm{C}$

\begin{tabular}{|c|c|c|c|c|c|c|c|}
\hline \multirow{3}{*}{ Isolate code } & \multicolumn{3}{|c|}{ Colony } & \multicolumn{4}{|c|}{ Growth rate } \\
\hline & \multirow{2}{*}{ shape } & \multirow{2}{*}{ reverse color } & \multirow{2}{*}{ edge } & \multicolumn{2}{|c|}{ PDA } & \multicolumn{2}{|c|}{ SNA } \\
\hline & & & & $25^{\circ} \mathrm{C}$ & $30^{\circ} \mathrm{C}$ & $25^{\circ} \mathrm{C}$ & $30^{\circ} \mathrm{C}$ \\
\hline EGY-T1 & circular & green & smooth & $5.24^{\text {fghij }}$ & $4.90^{\text {hijklmnop }}$ & $3.76^{\text {bcdefg }}$ & $2.86^{\mathrm{jkl}}$ \\
\hline EGY-T2 & serrate & white & wavy & $5.00^{\text {hij }}$ & $4.64^{\text {mnopqr }}$ & $2.44^{\text {mnopq }}$ & $2.38^{\mathrm{m}}$ \\
\hline EGY-T3 & circular & yellow & smooth & $6.36^{\mathrm{a}}$ & $6.10^{\mathrm{a}}$ & $3.74^{\text {bcdefg }}$ & $3.90^{\mathrm{ab}}$ \\
\hline EGY-T4 & circular & light green & smooth & $5.72^{\text {cdef }}$ & 5.16 & $3.49^{\mathrm{mnopq}}$ & $3.00^{\text {hij }}$ \\
\hline EGY-T5 & circular & yellow & smooth & $5.98^{\mathrm{abc}}$ & $5.58^{\mathrm{ab}}$ & $3.36^{\text {efghij }}$ & $3.34^{\text {defgh }}$ \\
\hline EGY-T6 & circular & dark green & smooth & $4.90^{\mathrm{j}}$ & $5.26^{\text {cdefgh }}$ & $3.20^{\text {ghijkl }}$ & $3.82^{\mathrm{abc}}$ \\
\hline EGY-T7 & circular & white & smooth & $5.38^{\text {cdefghij }}$ & $4.96^{\text {ghijklmno }}$ & $4.12^{\mathrm{abcd}}$ & $3.08^{\text {ghij }}$ \\
\hline EGY-T8 & serrate & white & wavy & $5.30^{\text {defghij }}$ & $4.60^{\text {opqr }}$ & $2.58^{\operatorname{lmnopq}}$ & $1.74^{\text {nop }}$ \\
\hline EGY-T9 & circular & yellow & wavy & $5.42^{\text {bcdefghij }}$ & $4.30^{\mathrm{r}}$ & $2.94^{\mathrm{ijklmn}}$ & $3.60^{\text {bcde }}$ \\
\hline EGY-T10 & serrate & white & smooth & $5.52^{\text {cdefghij }}$ & $3.94^{\mathrm{s}}$ & $4.26^{\mathrm{ab}}$ & $1.24^{\mathrm{q}}$ \\
\hline EGY-T11 & circular & green & smooth & $5.48^{\text {cdefghij }}$ & $5.00^{\text {efghijklm }}$ & $2.62^{\operatorname{lmnopq}}$ & $1.60^{\mathrm{op}}$ \\
\hline EGY-T12 & serrate & white & wavy & $5.32^{\text {defghij }}$ & $4.84^{\mathrm{ijklmnop}}$ & $2.08^{\mathrm{q}}$ & $1.96^{\mathrm{n}}$ \\
\hline EGY-T13 & circular & yellow & wavy & $5.70^{\text {cdef }}$ & $5.66^{\mathrm{b}}$ & $3.62^{\text {cdefgh }}$ & $3.60^{\text {bcde }}$ \\
\hline EGY-T14 & circular & light green & smooth & $5.64^{\text {cdefgh }}$ & $5.16^{\text {defghijk }}$ & $2.64^{\operatorname{lmnopq}}$ & $3.56^{\text {bcde }}$ \\
\hline EGY-T15 & circular & light green & smooth & $5.44^{\text {bcdefghij }}$ & $5.26^{\text {cdefgh }}$ & $3.88^{\text {abcdef }}$ & $4.10^{\mathrm{a}}$ \\
\hline EGY-T16 & serrate & light yellow & wavy & $5.48^{\text {cdefghij }}$ & $4.70^{\text {mnopq }}$ & $2.84^{\text {jklmnop }}$ & $2.34^{\mathrm{m}}$ \\
\hline EGY-T17 & serrate & off-white & smooth & $5.30^{\text {efghij }}$ & $4.74^{\text {lmnop }}$ & $2.50^{\mathrm{mnopq}}$ & $1.86^{\mathrm{no}}$ \\
\hline EGY-T18 & circular & dark green & smooth & $5.60^{\text {cdefgh }}$ & $5.34^{\text {bcdef }}$ & $3.28^{\text {fghijk }}$ & $3.50^{\text {cdef }}$ \\
\hline EGY-T19 & cylindrical & light green & smooth & $5.04^{\text {ghij }}$ & $4.58^{\mathrm{pqr}}$ & $3.86^{\text {bcdef }}$ & $2.86^{\mathrm{jkl}}$ \\
\hline EGY-T20 & circular & light green & wavy & $5.48^{\text {cdefghij }}$ & $4.98^{\text {fghijklmn }}$ & $3.54^{\text {defghi }}$ & $2.70^{\mathrm{kl}}$ \\
\hline EGY-T21 & circular & light green & smooth & $5.38^{\text {cdefghij }}$ & $4.72^{\mathrm{mnopq}}$ & $3.78^{\text {bcdefg }}$ & $3.56^{\text {bcde }}$ \\
\hline EGY-T22 & circular & dark yellow & smooth & $5.80^{\text {abcde }}$ & $4.92^{\text {hijklmnop }}$ & $3.76^{\text {bcdefg }}$ & $4.10^{\mathrm{a}}$ \\
\hline EGY-T23 & serrate & white & wavy & $4.94^{\mathrm{ij}}$ & $4.36^{\mathrm{qr}}$ & $3.76^{\text {bcdefg }}$ & $3.20^{\text {fghi }}$ \\
\hline EGY-T24 & cylindrical & dark green & smooth & $5.64^{\text {cdefgh }}$ & $4.68^{\mathrm{mnopq}}$ & $3.44^{\text {efghij }}$ & $3.66^{\mathrm{bcd}}$ \\
\hline EGY-T25 & circular & dark green & smooth & $5.60^{\text {cdefgh }}$ & $5.18^{\text {defghij }}$ & $3.04^{\text {hijklm }}$ & $3.50^{\text {cdef }}$ \\
\hline EGY-T26 & circular & light green & smooth & $5.22^{\text {fghij }}$ & $5.30^{\text {bcdefg }}$ & $2.24^{\mathrm{pq}}$ & $3.56^{\text {bcde }}$ \\
\hline EGY-T27 & serrate & yellow & wavy & $4.88^{\mathrm{j}}$ & $4.38^{\mathrm{qr}}$ & $2.68^{\mathrm{klmnopq}}$ & $2.94^{\mathrm{ijk}}$ \\
\hline EGY-T28 & serrate & dark green & wavy & $5.64^{\text {cdefgh }}$ & $4.76^{\text {lmnop }}$ & $2.70^{\mathrm{klmnopq}}$ & $3.26^{\text {efghi }}$ \\
\hline EGY-T29 & serrate & yellow & wavy & $5.38^{\text {cdefghij }}$ & $4.36^{\mathrm{qr}}$ & $3.94^{\text {abcde }}$ & $2.86^{\mathrm{jkl}}$ \\
\hline EGY-T30 & serrate & dark yellow & wavy & $4.94^{\mathrm{ij}}$ & $4.62^{\text {nopqr }}$ & $3.62^{\text {cdefgh }}$ & $2.54^{\operatorname{lm}}$ \\
\hline EGY-T31 & circular & yellow & smooth & $5.50^{\text {cdefghij }}$ & $5.20^{\text {defghi }}$ & $2.92^{\mathrm{ijklmno}}$ & $3.34^{\text {defgh }}$ \\
\hline EGY-T32 & serrate & light green & smooth & $5.60^{\text {cdefghi }}$ & $3.90^{\mathrm{s}}$ & $4.20^{\mathrm{abc}}$ & $3.20^{\text {fghi }}$ \\
\hline EGY-T33 & circular & yellow & wavy & $6.02^{\mathrm{ab}}$ & $5.50^{\mathrm{abc}}$ & $2.84^{\text {jklmnop }}$ & $3.90^{\mathrm{ab}}$ \\
\hline EGY-T34 & circular & light green & smooth & $5.52^{\text {cdefghij }}$ & $5.48^{\mathrm{bcd}}$ & $2.90^{\mathrm{jklmno}}$ & $3.90^{\mathrm{ab}}$ \\
\hline EGY-T35 & cylindrical & light green & smooth & $5.98^{\mathrm{abc}}$ & $5.10^{\text {efghijkl }}$ & $2.56^{\mathrm{mnopq}}$ & $1.46^{\mathrm{pq}}$ \\
\hline EGY-T36 & circular & yellow & smooth & $5.92^{\text {abcd }}$ & $5.60^{\mathrm{ab}}$ & $3.58^{\text {defgh }}$ & $3.90^{\mathrm{ab}}$ \\
\hline EGY-T37 & cylindrical & light green & smooth & $4.86^{\mathrm{j}}$ & $4.84^{\mathrm{ijk} k l m n o p}$ & $3.30^{\mathrm{opq}}$ & $3.60^{\text {bcde }}$ \\
\hline EGY-T38 & circular & yellow & smooth & $5.84^{\text {abcde }}$ & $5.56^{\mathrm{ab}}$ & $3.20^{\text {ghijkl }}$ & $3.40^{\text {defg }}$ \\
\hline EGY-T39 & circular & white & smooth & $4.04^{\mathrm{k}}$ & $4.80^{\text {klmnop }}$ & $4.46^{\mathrm{a}}$ & $3.60^{\text {bcde }}$ \\
\hline EGY-T40 & cylindrical & green & wavy & $3.38^{1}$ & $4.82^{\mathrm{jklmnop}}$ & $2.32^{\text {nopq }}$ & $1.66^{\text {nop }}$ \\
\hline
\end{tabular}


A

Different strains after 2 days on PDA at $30^{\circ} \mathrm{C}$
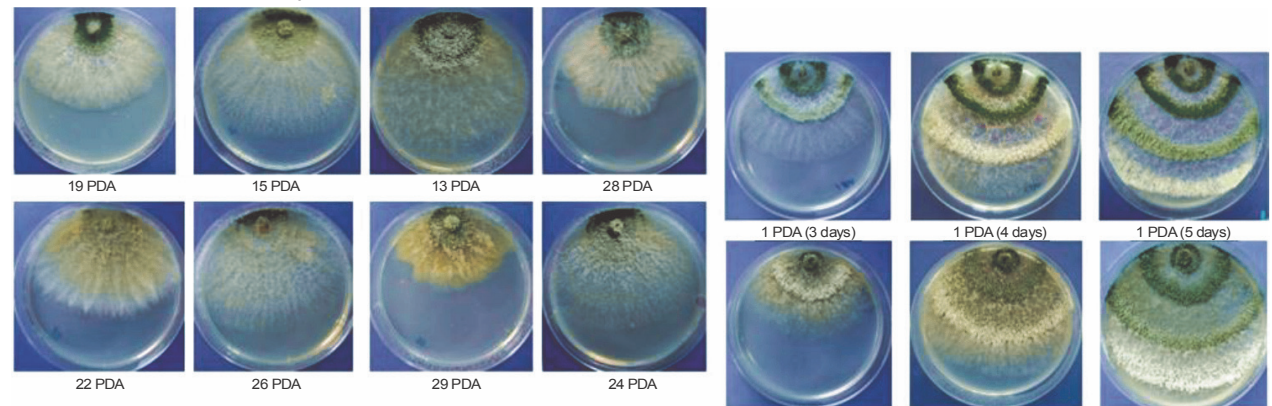

ferent strains after 4 days on PDA at $30^{\circ} \mathrm{C}$
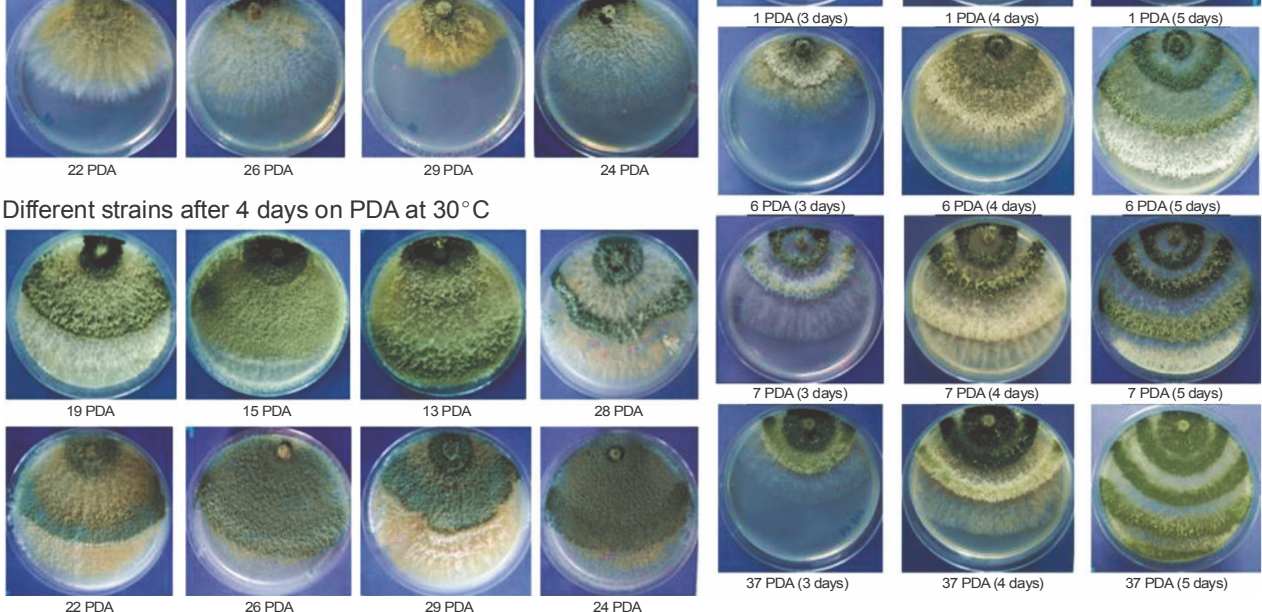

$B$

C
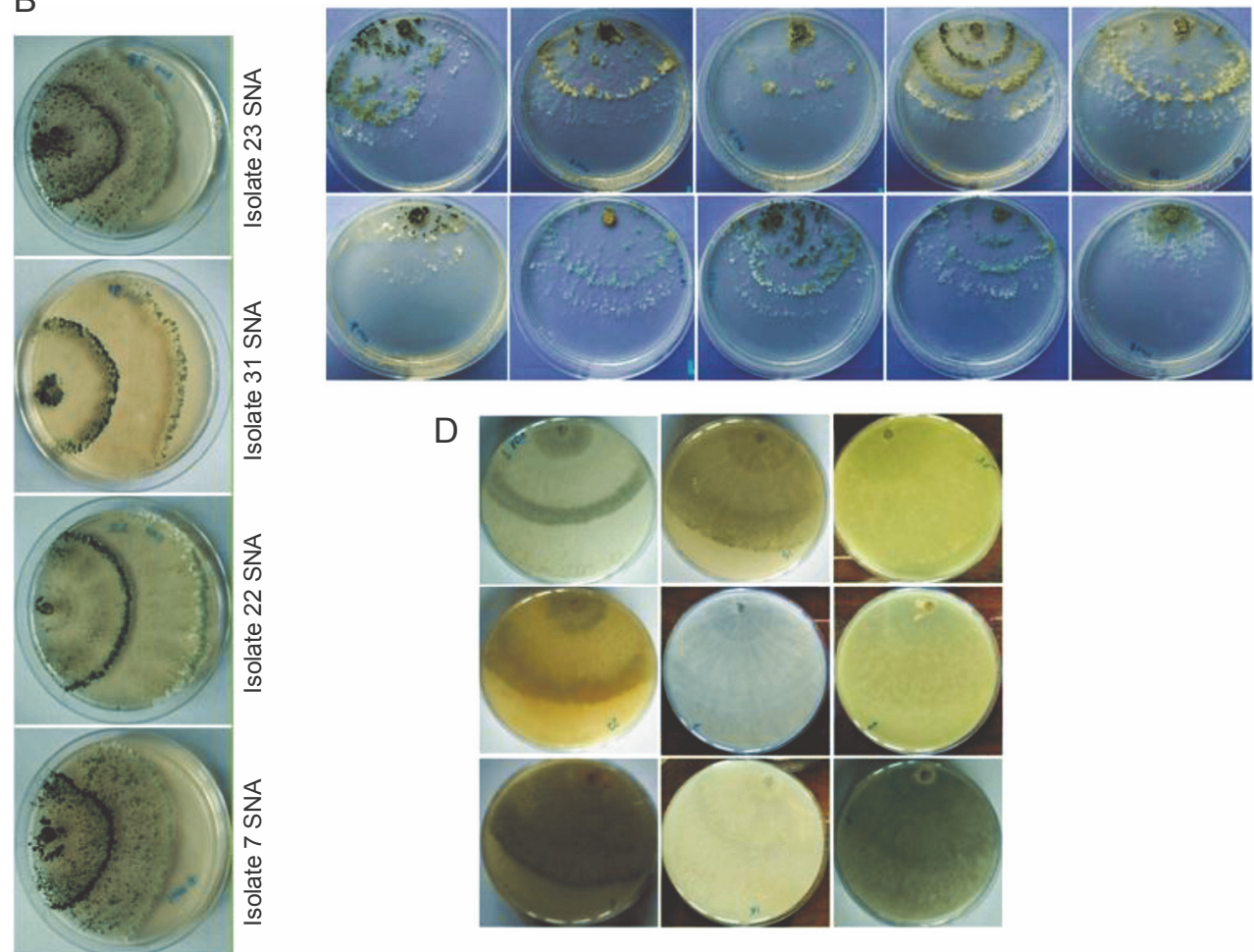

D

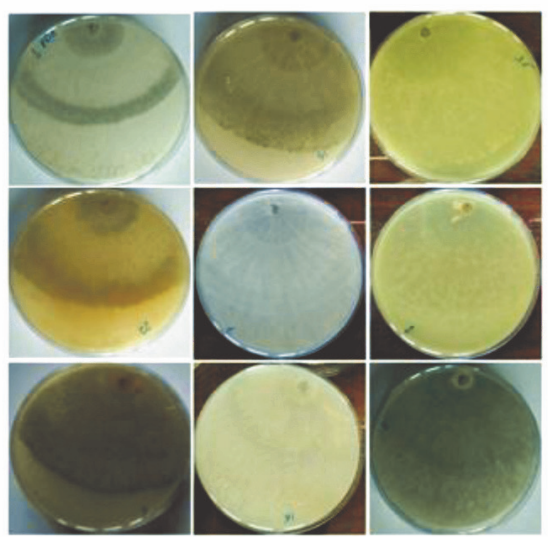

Fig. 2. Morphological characteristics of different Trichoderma isolates on PDA and SNA growth media to illustrate the growth rate and reverse color of each Trichoderma isolate: A) different fungal cultures on PDA after 2, 3, 4, and 5 days of growth, incubated at $30^{\circ} \mathrm{C}, \mathrm{B}$ and $\mathrm{C}$ ) cultures of different Trichoderma isolates on SNA after 5 days of growth, incubated at $30^{\circ} \mathrm{C}$ and $25^{\circ} \mathrm{C}$, respectively, D) different pigment colors of each Trichoderma fungi grown on PDA at $30^{\circ} \mathrm{C}$ (reverse plate) 
Among the several molecular methods used to characterize fungal species, sequence analysis of the ITS region is the most commonly used molecular marker analysis (Dashtban and Qin, 2012). In eukaryotic cells, there are two ITSs flanking the $5.8 \mathrm{~S}$ gene. The two spacers, together with the $5.8 \mathrm{~S}$ gene, are normally referred to as the ITS region. The rRNA genes are universally conserved, while the ITS region and intergenic spacer (IGS) are highly variable (Lieckfeldt et al., 2002). Thus, the sequences of these regions can be effectively used for the identification of closely related species (White et al., 1990). The lengths of ITS4 and ITS5 ranged from 364 to $596 \mathrm{bp}$ for T. viride (MH908510) and T. longibrachiatum (MH908502), respectively. In addition, EGY-T12, T36, and T38 ( $T$. afroharzianum) and EGY-T23 and T28 (Trichoderma spp.) had the same size of ITS sequences of 576 bp (Table 4). Furthermore, EGY-T20 and T21 (579 bp) had the same size of ITS as EGY-T6 and EGYT13 (575 bp); however, after sequencing analyses, they were identified as different species (Trichoderma spp., T. harzianum, T. aureoviride). In general, the 27 identified isolates belonged to Trichoderma. Moreover, seven species were classified as $T$. harzianum and five as $T$. asperellum. The strains showed clear variations in the growth rates probably due to the diversity of strains and the collection sources from different geographic locations in Egypt. To determine the phylogenetic positions of the Trichoderma isolates, sequence alignments of 5.8S-ITS and tef 1 gene regions with the fungal strains were performed using the Basic Local Alignment Search Tool (BLAST). These fungal strains were identified on the basis of the NCBI taxonomy database using BLASTN search results (\% identify and alignment length) within clades with acceptable quality for ITS sequences ranging from $98 \%$ to $100 \%$, except for T. asperellum (MH908499) - 85\%; three Trichoderma species remained unidentified. The result of the phylogenetic analysis of ITS sequence data is given in Figure 3A. The maximum parsimony bootstrap value for ITS was 100 , while for tef1 (Fig. 3B), it ranged from $95 \%$ to $100 \%$. The cluster of Trichoderma spp. based on both ITS and tef1 data was divided into two principal groups. The nucleotide ITS sequences of the 27 strains are presented in Figure 3C. The results revealed that the sequence fragments of ITS and tef 1 were highly similar in Trichoderma species as shown in Table 3. The proportion and composition of Trichoderma species varied between soil samples taken from different provinces and depended on both crop residues and soil type.

\section{Screening of Trichoderma isolates for cellulase activity}

Forty isolates of Trichoderma were evaluated for endoglucanase activity and production of exoglucanase enzymes. Three cellulose substrates were used to test the cellulase activity of the studied strains, i.e., CMC with Congo red dye assessed by the formation of clear zone diameters; another assay was conducted for the determination of endonuclease activities by using the plate clearing assay of acid swollen cellulose (Swollen) as the substrate. Screening of highly producing exoglucanase isolates was performed using microcrystalline cellulose (Avicel) as the substrate. The isolates showed significant differences in cellulase activity as shown in Table 5 and Figure 4. T. viride (MH908510) had the highest endoglucanase activity after incubation for 7 days on both Swollen and CMC cellulose substrates, with a growth rate of 4.70 and $5.15 \mathrm{~cm}$, respectively. $T$. harzianum (MH908512), T. afroharzianum (MH908513), and T. asperellum (MH908494) showed the highest exoglucanase activity on Avicel substrate observed as growth zones of $7.10,6.35$, and $6.35 \mathrm{~cm}$, respectively. T. asperellum (MH908497) showed the lowest endoglucanase activity on Swollen substrate with the growth rate of $1.60 \mathrm{~cm}$, and T. afroharzianum (MH908509) exhibited the lowest exoglucanase activity when inoculated on Avicel substrate with the growth rate of $2.80 \mathrm{~cm}$.

\section{Discussion}

A total of 40 Trichoderma isolates were obtained from rhizosphere soil samples of cultivated fields from different locations in Egypt (Table 1). Identification, evaluation of optimum in vitro growth conditions, and cellulase production assessment were carried out in the present study to sift through Trichoderma isolates to find candidate strains with high cellulolytic activity. These strains can be beneficial for converting agricultural biomass to glucose, the essential substrate in the microbial production of bioethanol. Trichoderma isolates showed a distinct variation in their phenotypic characteristics in culture media along with apparent differences in cellulase activity. Sequence analysis of these strains revealed three new taxa in soil samples from different Egyptian habitats. It has been suggested that the diversity of soil sample locations might play a role in 
Table 3. Isolate codes and GenBank accession numbers of Trichoderma strains using two molecular markers ITS and tef1 sequences

\begin{tabular}{|c|c|c|c|}
\hline Isolate code & NCBI accession no. ITS & Strains (ITS) & Strains (tef 1 ) \\
\hline EGY-T1 & MH908491 & Trichoderma asperelloides & Trichoderma asperelloides \\
\hline EGY-T2 & MH908492 & Trichoderma asperellum & Trichoderma asperellum \\
\hline EGY-T3 & MH908493 & Trichoderma harzianum & Trichoderma harzianum \\
\hline EGY-T4 & MH908494 & Trichoderma asperellum & Trichoderma asperellum \\
\hline EGY-T5 & MH908495 & Trichoderma harzianum & Trichoderma harzianum \\
\hline EGY-T6 & MH908496 & Trichoderma harzianum & Trichoderma afroharzianum \\
\hline EGY-T7 & MH908497 & Trichoderma asperellum & Trichoderma asperellum \\
\hline EGY-T8 & MH908498 & Trichoderma harzianum & Trichoderma afroharzianum \\
\hline EGY-T9 & - & - & - \\
\hline EGY-T10 & - & - & - \\
\hline EGY-T11 & MH908499 & Trichoderma asperellum & \\
\hline EGY-T12 & MH908500 & Trichoderma afroharzianum & Trichoderma afroharzianum \\
\hline EGY-T13 & MH908501 & Trichoderma aureoviride & Trichoderma sp. \\
\hline EGY-T14 & MH908502 & Trichoderma longibrachiatum & - \\
\hline EGY-T15 & - & - & - \\
\hline EGY-T16 & - & - & - \\
\hline EGY-T17 & MH908503 & Trichoderma asperellum & - \\
\hline EGY-T18 & MH908504 & Trichoderma afroharzianum & - \\
\hline EGY-T19 & - & - & - \\
\hline EGY-T20 & MH908505 & Trichoderma $s p$ & Trichoderma harzianum \\
\hline EGY-T21 & MH908506 & Trichoderma harzianum & Trichoderma harzianum \\
\hline EGY-T22 & - & - & - \\
\hline EGY-T23 & MH908507 & Trichoderma sp. & Trichoderma afroharzianum \\
\hline EGY-T24 & MH908508 & Trichoderma afroharzianum & Trichoderma afroharzianum \\
\hline EGY-T25 & MH908509 & Trichoderma afroharzianum & Trichoderma afroharzianum \\
\hline EGY-T26 & - & - & - \\
\hline EGY-T27 & MH908510 & Trichoderma viride & Hypocrea lixii \\
\hline EGY-T28 & MH908511 & Trichoderma sp. & Trichoderma afroharzianum \\
\hline EGY-T29 & - & - & Trichoderma afroharzianum \\
\hline EGY-T30 & MH908512 & Trichoderma harzianum & Trichoderma harzianum \\
\hline EGY-T31 & MH908513 & Trichoderma afroharzianum & Trichoderma afroharzianum \\
\hline EGY-T32 & MH908514 & Trichoderma harzianum & - \\
\hline EGY-T33 & - & - & - \\
\hline EGY-T34 & - & - & - \\
\hline EGY-T35 & - & - & - \\
\hline EGY-T36 & MH908515 & Trichoderma afroharzianum & Trichoderma afroharzianum \\
\hline EGY-T37 & & & Trichoderma afroharzianum \\
\hline EGY-T38 & MH908516 & Trichoderma afroharzianum & Trichoderma afroharzianum \\
\hline EGY-T39 & - & - & - \\
\hline EGY-T40 & MH908517 & Trichoderma atrobrunneum & - \\
\hline
\end{tabular}


A

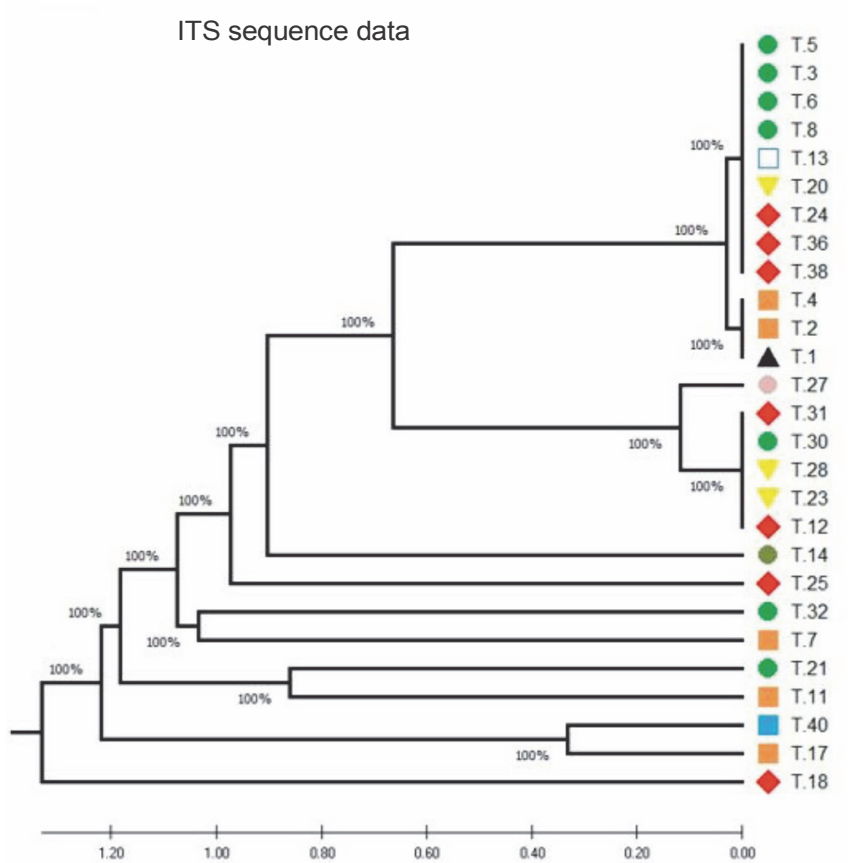

B

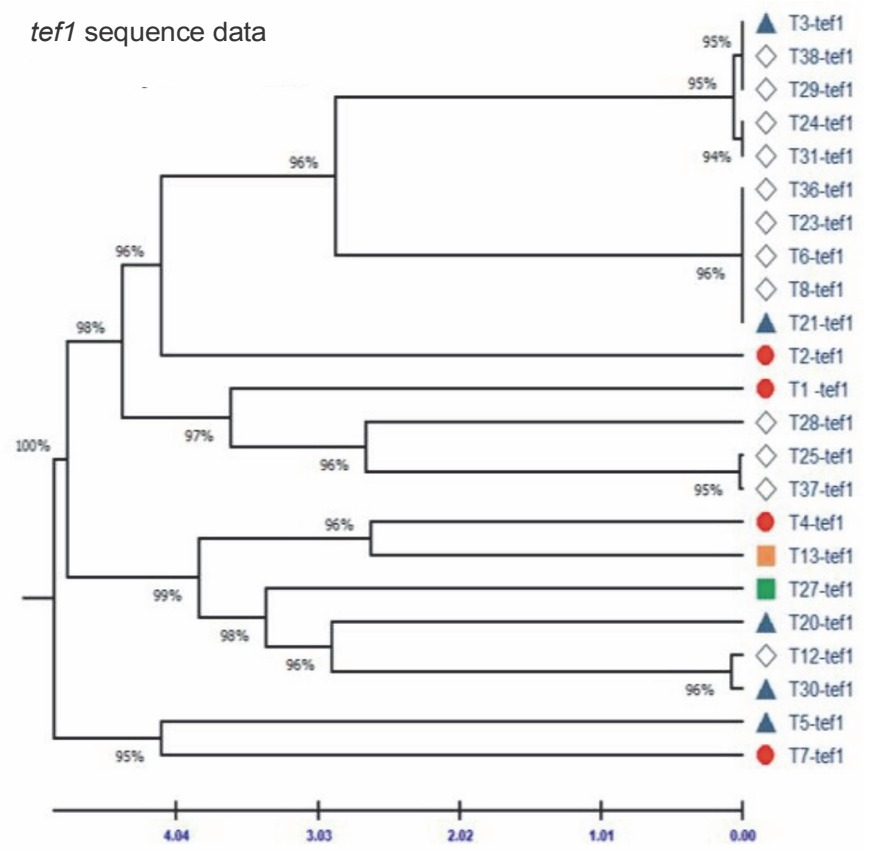

C

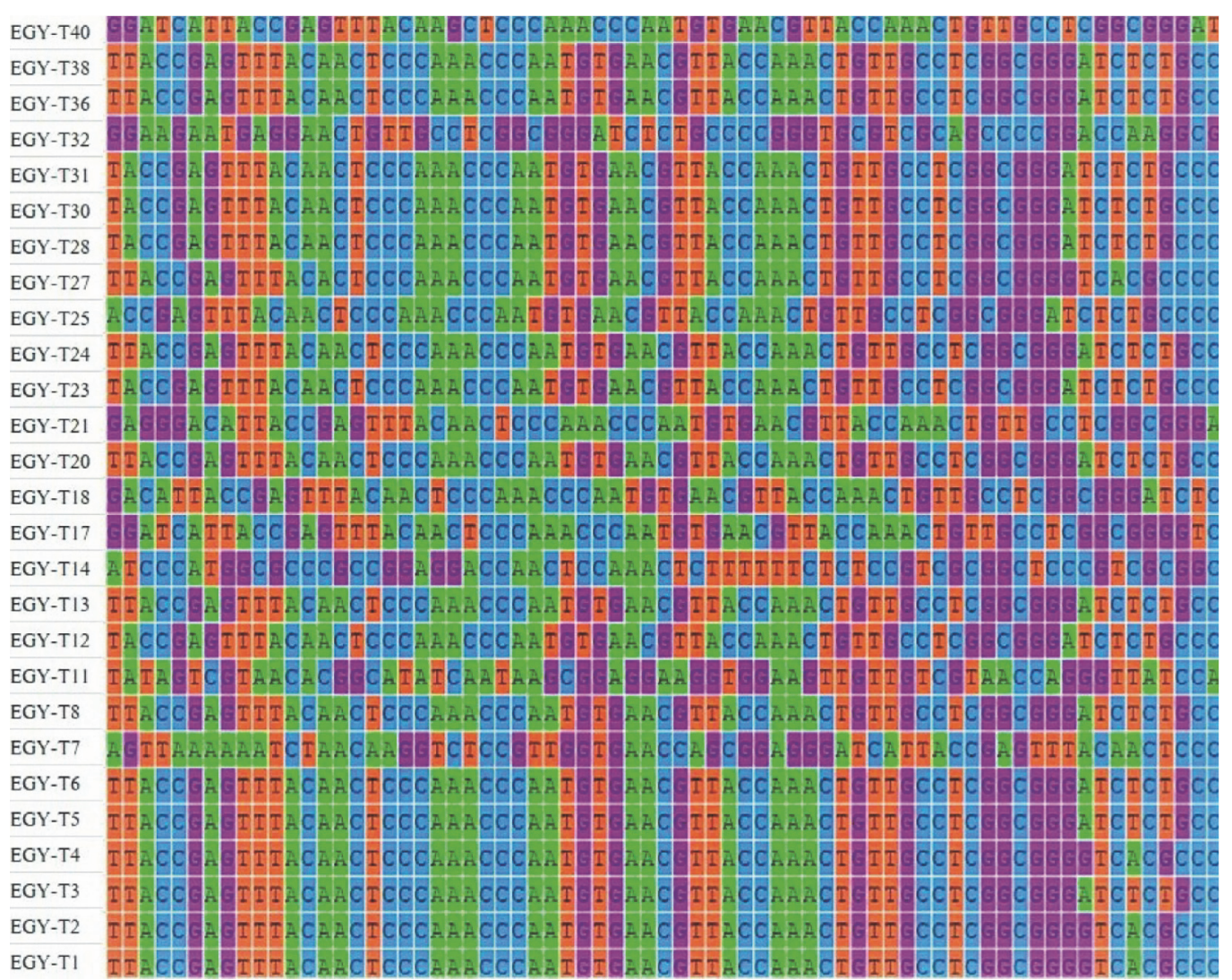

Fig. 3. Phylogenetic trees inferred from ITS rDNA and tef1 sequences. A and B) neighbor-joining analysis of identified isolates using ITS and tef1 sequence data sets individually by MEGA7 (each color on the phylogenetic tree means the same Trichoderma strain),

C) the alignment sequences based on ITS identification of Trichoderma isolates 
Table 4. ITS length and DNA/GC-content of the identified Trichoderma isolates

\begin{tabular}{|c|c|c|c|c|c|c|}
\hline Isolate code & $\begin{array}{c}\mathrm{A} \\
{[\%]}\end{array}$ & $\begin{array}{c}\mathrm{T} \\
{[\%]}\end{array}$ & $\begin{array}{l}\mathrm{C} \\
{[\%]}\end{array}$ & $\begin{array}{c}\mathrm{G} \\
{[\%]}\end{array}$ & $\begin{array}{c}\mathrm{G}+\mathrm{C} \\
{[\mathrm{mol} \%]}\end{array}$ & $\begin{array}{c}\text { ITS query length } \\
{[\mathrm{bp}]}\end{array}$ \\
\hline EGY-T1 & 24.3 & 21.4 & 34.3 & 20 & 54.3 & 583 \\
\hline EGY-T2 & 24.3 & 21.4 & 34.3 & 20 & 54.3 & 571 \\
\hline EGY-T3 & 24.3 & 24.3 & 32.9 & 18.6 & 51.5 & 572 \\
\hline EGY-T4 & 24.3 & 21.4 & 34.3 & 20 & 54.3 & 560 \\
\hline EGY-T5 & 24.3 & 24.3 & 32.9 & 18.6 & 51.5 & 590 \\
\hline EGY-T6 & 24.3 & 24.3 & 32.9 & 18.6 & 51.5 & 575 \\
\hline EGY-T7 & 32.9 & 22.9 & 22.9 & 21.4 & 44.3 & 568 \\
\hline EGY-T8 & 24.3 & 24.3 & 32.9 & 18.6 & 51.5 & 593 \\
\hline EGY-T9 & - & - & - & - & - & - \\
\hline EGY-T10 & - & - & - & - & - & - \\
\hline EGY-T11 & 30 & 25.7 & 15.7 & 28.6 & 44.3 & 511 \\
\hline EGY-T12 & 24.3 & 22.9 & 34.3 & 18.6 & 52.9 & 576 \\
\hline EGY-T13 & 24.3 & 24.3 & 32.9 & 18.6 & 51.5 & 575 \\
\hline EGY-T14 & 12.9 & 22.9 & 41.4 & 22.9 & 64.3 & 364 \\
\hline EGY-T15 & - & - & - & - & - & - \\
\hline EGY-T16 & - & - & - & - & - & - \\
\hline EGY-T17 & 27.1 & 22.9 & 28.6 & 21.4 & 50 & 584 \\
\hline EGY-T18 & 27.1 & 24.3 & 30 & 18.6 & 48.6 & 577 \\
\hline EGY-T19 & - & - & - & - & - & - \\
\hline EGY-T20 & 24.3 & 24.3 & 32.9 & 18.6 & 51.5 & 579 \\
\hline EGY-T21 & 28.6 & 21.4 & 27.1 & 22.9 & 50 & 579 \\
\hline EGY-T22 & - & - & - & - & - & - \\
\hline EGY-T23 & 24.3 & 22.9 & 34.3 & 18.6 & 52.9 & 576 \\
\hline EGY-T24 & 24.3 & 24.3 & 32.9 & 18.6 & 51.5 & 594 \\
\hline EGY-T25 & 24.3 & 21.4 & 34.3 & 20 & 54.3 & 592 \\
\hline EGY-T26 & - & - & - & - & - & - \\
\hline EGY-T27 & 22.9 & 21.4 & 34.3 & 21.4 & 55.7 & 596 \\
\hline EGY-T28 & 24.3 & 22.9 & 34.3 & 18.6 & 52.9 & 576 \\
\hline EGY-T29 & - & - & - & - & - & - \\
\hline EGY-T30 & 24.3 & 22.9 & 34.3 & 18.6 & 52.9 & 574 \\
\hline EGY-T31 & 24.3 & 22.9 & 34.3 & 18.6 & 52.9 & 578 \\
\hline EGY-T32 & 17.1 & 14.3 & 31.4 & 37.1 & 68.5 & 546 \\
\hline EGY-T33 & - & - & - & - & - & - \\
\hline EGY-T34 & - & - & - & - & - & - \\
\hline EGY-T35 & - & - & - & - & - & - \\
\hline EGY-T36 & 24.3 & 24.3 & 32.9 & 18.6 & 51.5 & 576 \\
\hline EGY-T37 & - & - & - & - & - & - \\
\hline EGY-T38 & 24.3 & 24.3 & 32.9 & 18.6 & 51.5 & 576 \\
\hline EGY-T39 & - & - & - & - & - & - \\
\hline EGY-T40 & 27.1 & 22.9 & 28.6 & 21.4 & 50 & 582 \\
\hline
\end{tabular}


A
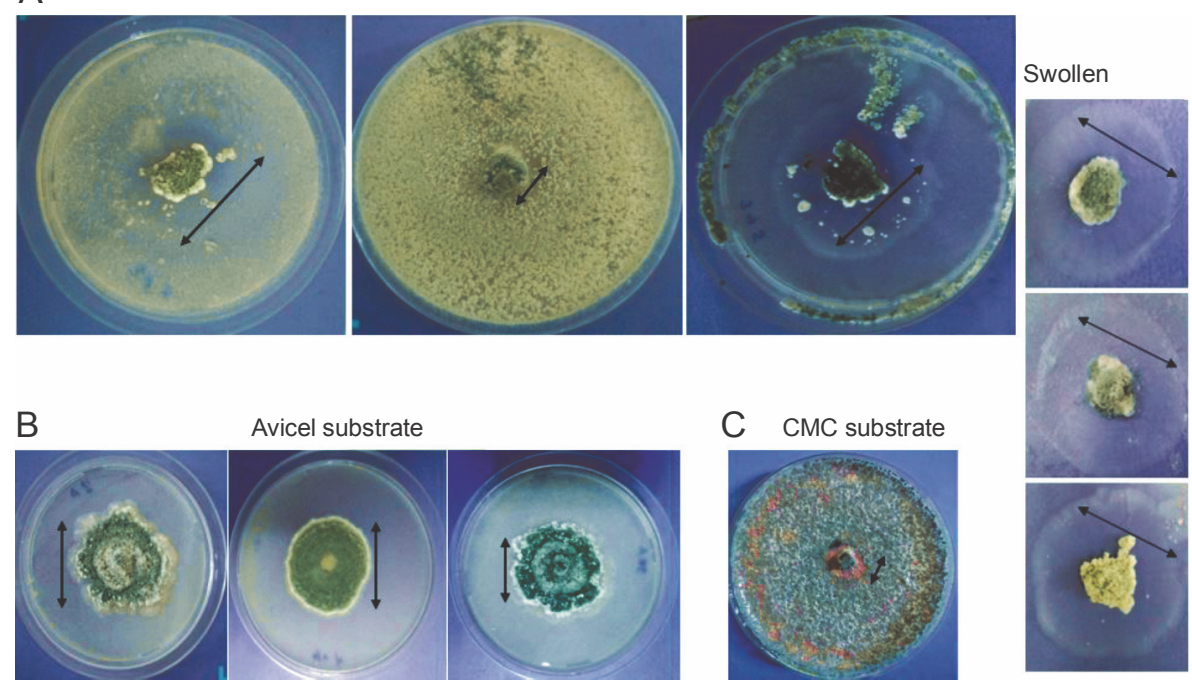

B

Avicel substrate
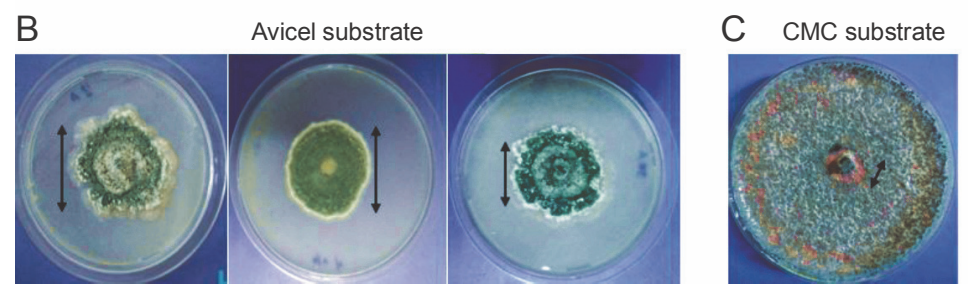

Fig. 4. Determination of Trichoderma isolates cellulase activity in vitro after 7 days of growth using different cellulose substrates: A) different growth zones of Trichoderma fungi using Swollen substrate, B) different growth rates of Trichodermaisolates on Avicel substrate, and C) Trichoderma EGY-T25 growth on CMC cellulose substrate

the variation of Trichoderma species (Rodrigues et al., 2014; Jiang et al., 2016). Because these strains were isolated from soil samples of different crop residues located at different regions in Egypt, the variation in cultivated crops and the isolation sources might also have an impact on the biodiversity of the fungal species. High level of Trichoderma biodiversity in the agricultural soil as observed in this study was based not only on morphological characteristics but also on molecular identification. The fungal diversity and the distribution pattern were influenced by different regions and crop types.

The cellulolytic activity of Trichoderma could be useful in the biofuel production process as it has been shown that Trichoderma could be used directly to hydrolyze cellulosic biomass to glucose, which is later fermented to produce bioethanol (Bu et al., 2019). Alternatively, these strains could act as a source for cellulases, thus reducing its production costs while increasing its sustainability (Libardi et al., 2017). In the present study, Trichoderma species were screened for the activity of cellulase enzymes using three cellulosic substrates: Swollen and CMC for endoglucanase and Avicel for exoglucanase. Libardi et al. (2017) reported that microcrystalline cellulose (Avicel) was the best inducer in terms of promoting high cellulase enzyme activity, and hence, it was used in the present study to assess cellulase activity as shown in Table 5 and Figure 4. Screening of cellulaseproducing microorganisms can be performed on agar plates by using a cellulosic substrate such as Avicel or carboxymethylcellulose (CMC) as carbon source for microorganism growth. To identify isolates producing high levels of endoglucanases, two methods were performed: CMC and swollen cellulose plate assay. CMC is used as it resembles cellulose; Congo red colorizes cellulose, and the area that is decolorized indicates the endoglucanase enzyme activity (Florencio et al., 2012). T. viride (Rafah isolate) had the highest cellulolytic activity for swollen and CMC (4.70 and $5.15 \mathrm{~cm}$, respectively), which is consistent with previous studies showing that $T$. viride has high cellulase activity (Penttilä et al., 1986; Fowler and Brown, 1992; Saloheimo et al., 2002). The use of Avicel revealed that T. harzianum (MH908512), T. afroharzianum (MH908513), and T. asperellum (MH908494) strains had the highest exoglucanase activity observed as 7.10, 6.35, and $6.35 \mathrm{~cm}$, respectively. Although Trichoderma species are well known as efficient cellulose degraders and have been widely studied, this fungus produces a limited amount of $\beta$-glucosidase for a complete and efficient industrial cellulose hydrolysis (Sørensen et al., 2013).

Growth rate is a morphological parameter to assess morphological characteristics, while morphological characterization and molecular identification are essential 
Table 5. Reported cellulase activity measurements of Trichoderma strains with PDA medium supplemented with different cellulose substrates after 7 days incubation at $28 \pm 2{ }^{\circ} \mathrm{C}$

\begin{tabular}{|c|c|c|c|}
\hline \multirow{2}{*}{ Isolate code } & \multicolumn{2}{|c|}{ Endoglucanase } & \multirow{2}{*}{$\frac{\text { Exoglucanase }}{\text { Avicel }}$} \\
\hline & Swollen & $\mathrm{CMC}$ & \\
\hline EGY-T1 & $3.25^{\text {defgh }}$ & $1.35^{\text {opq }}$ & $3.60^{\mathrm{ijkl}}$ \\
\hline EGY-T2 & $3.00^{\text {efghijkl }}$ & $1.25^{\mathrm{pq}}$ & $4.80^{\text {fgh }}$ \\
\hline EGY-T3 & $2.60^{\text {hijklm }}$ & $1.35^{\mathrm{opq}}$ & $4.90^{\mathrm{fg}}$ \\
\hline EGY-T4 & $2.25^{\operatorname{lmn}}$ & $1.75^{\mathrm{mnop}}$ & $6.35^{b c}$ \\
\hline EGY-T5 & $3.70^{\text {bcde }}$ & $1.00^{\mathrm{q}}$ & $3.60^{\mathrm{ijkl}}$ \\
\hline EGY-T6 & $3.05^{\text {efghijk }}$ & $1.10^{\mathrm{q}}$ & $6.10^{\mathrm{cd}}$ \\
\hline EGY-T7 & $1.60^{\mathrm{n}}$ & $4.65^{\mathrm{ab}}$ & $5.25^{\mathrm{ef}}$ \\
\hline EGY-T8 & $2.95^{\text {efghijkl }}$ & $1.80^{\operatorname{lmnop}}$ & $4.30^{\text {ghi }}$ \\
\hline EGY-T9 & $3.35^{\text {cdefgh }}$ & $1.40^{\mathrm{opq}}$ & $4.90^{\mathrm{fg}}$ \\
\hline EGY-T10 & $3.45^{\text {bcdef }}$ & $1.90^{\mathrm{klmno}}$ & $3.90^{\mathrm{ijk}}$ \\
\hline EGY-T11 & $3.25^{\text {defgh }}$ & $2.15^{\mathrm{jklmn}}$ & $3.75^{\mathrm{ijkl}}$ \\
\hline EGY-T12 & $2.35^{\mathrm{jklm}}$ & $1.10^{\mathrm{q}}$ & $3.35^{\mathrm{klm}}$ \\
\hline EGY-T13 & $3.15^{\text {defghi }}$ & $1.40^{\mathrm{opq}}$ & $3.50^{\mathrm{jkl}}$ \\
\hline EGY-T14 & $3.50^{\text {bcdef }}$ & $2.25^{\mathrm{ijklm}}$ & $4.10^{\text {hij }}$ \\
\hline EGY-T15 & $2.85^{\text {fghijklm }}$ & $1.40^{\mathrm{opq}}$ & $3.70^{\mathrm{ijkl}}$ \\
\hline EGY-T16 & $2.65^{\text {ghijklm }}$ & $3.35^{\text {defg }}$ & $5.25^{\mathrm{ef}}$ \\
\hline EGY-T17 & $3.10^{\text {defghij }}$ & $1.55^{\text {nopq }}$ & $5.10^{\text {ef }}$ \\
\hline EGY-T18 & $2.85^{\text {fghijklm }}$ & $1.60^{\text {nopq }}$ & $4.10^{\text {hij }}$ \\
\hline EGY-T19 & $2.85^{\text {fghijklm }}$ & $3.75^{\mathrm{cd}}$ & $5.15^{\text {ef }}$ \\
\hline EGY-T20 & $2.40^{\mathrm{ijklm}}$ & $2.75^{\text {ghij }}$ & $3.25^{\mathrm{klm}}$ \\
\hline EGY-T21 & $3.40^{\text {bcdefg }}$ & $2.45^{\text {hijk }}$ & $4.75^{\text {fgh }}$ \\
\hline EGY-T22 & $2.15^{\mathrm{mn}}$ & $4.25^{\mathrm{bc}}$ & $5.25^{\text {ef }}$ \\
\hline EGY-T23 & $4.10^{\mathrm{ab}}$ & $1.10^{\mathrm{q}}$ & $4.90^{\mathrm{fg}}$ \\
\hline EGY-T24 & $2.30^{\mathrm{klm}}$ & $2.85^{\text {fghi }}$ & $4.15^{\text {hij }}$ \\
\hline EGY-T25 & $3.00^{\text {efghijkl }}$ & $2.35^{\text {hijklm }}$ & $2.80^{\mathrm{m}}$ \\
\hline EGY-T26 & $3.25^{\text {defgh }}$ & $1.95^{\mathrm{klmno}}$ & $3.90^{\mathrm{ijk}}$ \\
\hline EGY-T27 & $4.70^{\mathrm{a}}$ & $5.15^{\mathrm{a}}$ & $5.65^{\mathrm{de}}$ \\
\hline EGY-T28 & $2.40^{\mathrm{ijklm}}$ & $2.40^{\text {hijkl }}$ & $4.80^{\text {fgh }}$ \\
\hline EGY-T29 & $2.40^{\mathrm{ijklm}}$ & $2.10^{\mathrm{klmn}}$ & $3.10^{\operatorname{lm}}$ \\
\hline EGY-T30 & $2.40^{\mathrm{ijklm}}$ & $2.30^{\text {hijklm }}$ & $7.10^{\mathrm{a}}$ \\
\hline EGY-T31 & $3.10^{\text {defghij }}$ & $3.75^{\mathrm{cd}}$ & $6.35^{\mathrm{bc}}$ \\
\hline EGY-T32 & $2.95^{\text {efghijkl }}$ & $3.35^{\text {defg }}$ & $5.10^{\mathrm{ef}}$ \\
\hline EGY-T33 & $3.10^{\text {defghij }}$ & $3.45^{\text {def }}$ & $5.25^{\text {ef }}$ \\
\hline EGY-T34 & $4.60^{\mathrm{a}}$ & $4.40^{\mathrm{b}}$ & $6.75^{\mathrm{ab}}$ \\
\hline EGY-T35 & $3.35^{\text {cdefgh }}$ & $4.35^{\mathrm{b}}$ & $6.10^{\text {bcd }}$ \\
\hline EGY-T36 & $3.85^{\mathrm{bcd}}$ & $3.60^{\mathrm{de}}$ & $5.20^{\text {ef }}$ \\
\hline EGY-T37 & $3.60^{\text {bcdef }}$ & $2.90^{\text {fgh }}$ & $3.85^{\mathrm{ijk}}$ \\
\hline EGY-T38 & $4.05^{\mathrm{abc}}$ & $3.10^{\text {efg }}$ & $4.65^{\text {fgh }}$ \\
\hline EGY-T39 & $3.35^{\text {cdefgh }}$ & $2.85^{\text {fghi }}$ & $5.15^{\text {ef }}$ \\
\hline EGY-T40 & $3.10^{\text {defghij }}$ & $1.90^{\mathrm{klmno}}$ & $4.10^{\text {hij }}$ \\
\hline
\end{tabular}

*Values within a column followed by the same letter (s) are not significantly different at the $P=0.05$ level according to Duncan's multiple range test 
to confirm the taxonomy of the strains (Montoya et al., 2016). Based on the findings our study, the dominant species in the Egyptian soil samples were $T$. harzianum (7 strains) and $T$. afroharzianum ( 7 strains). Interestingly, the relationship between Harzianum clad dominance and their geographical locations might be due to both soil type and soil temperature. T. harzianum strains were isolated from loamy soils, and the optimum temperature for their growth ranged from 20 to $30^{\circ} \mathrm{C}$. T. harzianum has worldwide distribution and is often the dominant species in many environments (Gherbawy et al., 2004; Sadfi-Zouaoui et al., 2009).

To identify unknown isolates, previous investigations on Trichoderma fungi used only classical taxonomic methods (morphological markers) or molecular markers using the sequence of the ITS region (Fisher et al., 1996; BARBOSA., 2004; Rodrigues et al., 2014). Morphological identification presents serious problems when used as the only tool for species identification in the genus Trichoderma (Chaverri et al., 2003; Druzhinina and Kubicek, 2005a). On the other hand, using only ITS as a taxonomical method of describing unknown Trichoderma isolates as a molecular tool can cause inaccurate identification with insufficient intraspecific variability (Atanasova et al., 2013; Chaverri et al., 2015). Hence, the combination of morphological and molecular characterization is more reliable for the classification of different strains (Taylor et al., 2000; Druzhinina and Kubicek, 2005a; Atanasova et al., 2013; Chaverri et al., 2015). Additionally, to enhance the accuracy of molecular classification, another molecular marker was used for sequencing these isolates: the tef 1 gene. These biodiverse isolates collected from different soils, crops, and locations are highly valuable for Trichoderma research through mapping the distribution of Trichoderma strains in Egyptian soils. The next step is further investigation to confirm the novelty of these taxa and field application with various agricultural wastes.

\section{Conclusions}

This research is the most comprehensive study to screen for biodegrading Trichoderma strains from several Egyptian locations and to study their potential in converting agricultural crop residues to bioproducts. This is one of the most important and pressing issues currently in developing countries and worldwide in general.
Hence, the present study adds knowledge on the diversity of Trichoderma strains in Egypt. On the basis of taxonomic and cellulase activity of the isolated strains, the selection of the most promising strains is possible.

\section{Author contributions}

Omar Hewedy, the main author carried out all experiments, collected, assemble data, design the study, and wrote the manuscript. A. Fahmi developed the research concept and applied for the grant used to fund this work. A. El-Zanaty performed data analysis and interpretation. All authors read and approved the final manuscript.

\section{Acknowledgment}

We would like to express our thanks to Menoufia University for supporting this research by grants to Prof. A.I. Fahmi. In addition, O.A. Hewedy would like to thank the Laboratory of Biotechnology, Horticulture Research Institute, Agricultural Research Center, Egypt, for helping in molecular analysis.

\section{References}

Adsul M., Sandhu S.K., Singhania R.R., Gupta R., Puri S.K., Mathur A. (2019) Designing a cellulolytic enzyme cocktail for the efficient and economical conversion of lignocellulosic biomass to biofuels. Enzyme Microb. Technol. 109442.

Arnold A.E., Mejía L.C., Kyllo D. (2003) Fungal endophytes limit pathogen damage in a tropical tree. Proc. Nat. Acad. Sci. 100: 15649-15654.

Atanasova L., Druzhinina I.S., Jaklitsch W.M., Mukherjee P., Horwitz B., Singh U. (2013) Two hundred Trichoderma species recognized on the basis of molecular phylogeny. Trichoderma: biology and applications. CABI, Wallingford: 10-42.

Bailey B.A., Melnick R.L. (2013) The endophytic Trichoderma. Trichoderma: biology and applications. CABI, Wallingford: 152-172.

Barari H. (2016) Biocontrol of tomato Fusarium wilt by Trichoderma species under in vitro and in vivo conditions. Cercetari Agron. Moldova 49: 91-98.

Barbosa V.S. (2004) Efeito da fragmentaçao florestal na taxa de parasitismo de fungos associados ao jardim da formiga cortadeira Atta laevigata. Universidade Federal de Pernambuco.

Benítez T., Rincón A.M., Limón M.C., Codon A.C. (2004) Biocontrol mechanisms of Trichoderma strains. Intern. Microbiol. 7: 249-260.

Bu Y., Alkotaini B., Salunke B.K., Deshmukh A.R., Saha P., Kim B.S. (2019) Direct ethanol production from cellulose by consortium of Trichoderma reesei and Candida molischiana. Green Proces. Synth. 8Ł 416-420.

Case R.J., Boucher Y., Dahllöf I., Holmström C., Doolittle W.F., Kjelleberg S. (2007) Use of $16 S$ rRNA and rpoB genes as molecular markers for microbial ecology studies. Appl. Environ. Microbiol. 73: 278-288.

Chaverri P., Branco-Rocha F., Jaklitsch W., Gazis R., Degenkolb T., Samuels G.J. (2015) Systematics of the Tricho- 
derma harzianum species complex and the re-identification of commercial biocontrol strains. Mycologia 107: 558-590.

Chaverri P., Castlebury L.A., Overton B.E., Samuels G.J. (2003) Hypocrea/Trichoderma: species with conidiophore elongations and green conidia. Mycologia 95: 1100-1140.

Chaverri P., Samuels G.J. (2013) Evolution of habitat preference and nutrition mode in a cosmopolitan fungal genus with evidence of interkingdom host jumps and major shifts in ecology. Evolution 67: 2823-2837.

Chi M.-H., Park S.-Y., Lee Y.-H. (2009) A quick and safe method for fungal DNA extraction. Plant Pathol. J. 25: 108-111.

Dashtban M., Qin W. (2012) Overexpression of an exotic thermotolerant $\beta$-glucosidase in Trichoderma reesei and its significant increase in cellulolytic activity and saccharification of barley straw. Microbial Cell Fact. 11: 63.

Dashtban M., Schraft H., Qin W. (2009) Fungal bioconversion of lignocellulosic residues; opportunities \& perspectives. Inter. J. Biol. Sci. 5: 578.

De Souza M.F., Da Silva A.S.A., Bon E.P. (2018) A novel Trichoderma harzianum strain from the Amazon Forest with high cellulolyticcapacity. Biocatal.Agricult. Biotech. 14: 183-188.

Dodd S.L., Lieckfeldt E., Chaverri P., Overton B.E., Samuels G.J. (2002) Taxonomy and phylogenetic relationships of two species of Hypocrea with Trichoderma anamorphs. Mycol. Progr. 1: 409-428.

Druzhinina I., Kubicek C.P. (2005) Species concepts and biodiversity in Trichoderma and Hypocrea: from aggregate species to species clusters??. Zhejiang Univ. Sci. B 6: 100.

Druzhinina I.S., Chenthamara K., Zhang J. (2018) Massive lateral transfer of genes encoding plant cell wall-degrading enzymes to the mycoparasitic fungus Trichoderma from its plant-associated hosts. PLoS Gen. 14: e1007322.

Druzhinina I.S., Kopchinskiy A.G., Komoń M., Bissett J., Szakacs G., Kubicek C.P. (2005) An oligonucleotide barcode for species identification in Trichoderma and Hypocrea. Fungal Gen. Biol. 42: 813-828.

Druzhinina I.S., Kubicek C.P. (2017) Genetic engineering of Trichoderma reesei cellulases and their production. Microbial Biotech. 10Ł 1485-1499.

El-Zawahry Y., El-Mougith A., El-Saadani M., Hafez E., Soliman S. (2010) Partial purification and characterization of two endo- $\beta$-1, 4-glucanase from Trichoderma spp.(Shmosa tri). Aust. J. Basic Appl. Sci. 4: 4559-4568.

Elad Y., Chet I., Henis Y. (1981) A selective medium for improving quantitative isolation of Trichoderma spp. from soil. Phytoparasitica 9: 59-67.

Fahmi A., Eissa R., El-Halfawi K., Hamza H., Helwa M. (2016) Identification of Trichoderma spp. by DNA barcode and screening for cellulolytic activity. J. Microb. Biochem. Technol. 8: 202-209.

Fisher P., Stradling D., Sutton B., Petrini L. (1996) Microfungi in the fungus gardens of the leaf-cutting ant Atta cephalotes: a preliminary study. Mycol. Res. 100: 541-546.

Florencio C., Couri S., Farinas C.S. (2012) Correlation between agar plate screening and solid-state fermentation for the prediction of cellulase production by Trichoderma strains. Enzyme Res. doi: 10.1155/2012/793708
Fowler T., Brown R.D., (1992) The bgI1 gene encoding extracellular $\beta$ glucosidase from Trichoderma reesei is required for rapid induction of the cellulase complex. Mol. Microbiol. 6: 3225-3235.

Gherbawy Y., Druzhinina I., Shaban G.M. (2004) Trichoderma populations from alkaline agricultural soil in the Nile valley, Egypt, consist of only two species. Mycol. Progr. 3: 211-218.

Gomes I., Gomes J., Steiner W., Esterbauer H. (1992) Production of cellulase and xylanase by a wild strain of Trichoderma viride. Appl. Microbiol. Biotech. 36: 701-707.

Gordillo-Fuenzalida F., Echeverria-Vega A., Cuadros-Orellana S., Faundez C., Kähne T., Morales-Vera R. (2019) Cellulases production by a Trichoderma sp. using food manufacturing wastes. Appl. Sci. 9: 4419.

Gusakov A.V. (2013) Cellulases and hemicellulases in the 21st century race for cellulosic ethanol. Taylor \& Francis.

Harman G.E., Howell C.R., Viterbo A., Chet I., Lorito M. (2004) Trichoderma species - opportunistic, avirulent plant symbionts. Nature Rev. Microbiol. 2: 43.

Jiang Y., Wang J.L., Chen J. (2016) Trichoderma biodiversity of agricultural fields in east China reveals a gradient distribution of species. PLoS One 11.

Keshavarz B., Khalesi M. (2016) Trichoderma reesei, a superior cellulase source for industrial applications. Biofuels 7: 713-721.

Kim D.W., Jeong Y.K., Jang Y.H., Lee J.K. (1994) Purification and characterization of endoglucanase and exoglucanase components from Trichoderma viride. J. Ferment. Bioengin. 77: 363-369.

Kumar S., Stecher G., Tamura K. (2016) MEGA7: molecular evolutionary genetics analysis version 7.0 for bigger datasets. Mol. Biol. Evol. 33: 1870-1874.

Libardi N., Soccol C.R., Góes-Neto A., De Oliveira J., De Souza Vandenberghe L.P. (2017) Domestic wastewater as substrate for cellulase production by Trichoderma harzianum. Process. Biochem. 57: 190-199.

Lieckfeldt E., Kuhls K., Muthumeenakshi S. (2002) Molecular taxonomy of Trichoderma and Gliocladium and their teleomorphs. Trichoderma and Gliocladium Volume, 35.

Lloyd P. (2017) Sustainable agriculture for biodiversity, biodiversity for sustainable agriculture. Taylor \& Francis.

Mach R., Zeilinger S. (2003) Regulation of gene expression in industrial fungi: Trichoderma. Appl. Microbiol. Biotech. 60: 515-522.

Mandels M., Reese E.T. (1957) Induction of cellulase in Trichoderma viride as influenced by carbon sources and metals. J. Bacteriol. 73: 269.

Mishra V.K., (2010) In vitro antagonism of Trichoderma species against Pythium aphanidermatum. J. Phytol. 2(9): 28-35.

Möller E., Bahnweg G., Sandermann H., Geiger H. (1992) A simple and efficient protocol for isolation of high molecular weight DNA from filamentous fungi, fruit bodies, and infected plant tissues. Nucl. Acids Res. 20: 6115.

Montoya Q.V., Meirelles L.A., Chaverri P., Rodrigues A. (2016) Unraveling Trichoderma species in the attine ant 
environment: description of three new taxa. Antonie van Leeuwenhoek 109: 633-651.

Nirenberg H. (1976) Untersuchungen ber die morphologische und biologisch Diffrenzieerum in der Fusarium Sekion Lisiola. Mitteil. Biol. Bundesanst. Fr. Land Forstwirtsch. 169: 1117.

Penttilä M., Lehtovaara P., Nevalainen H., Bhikhabhai R., Knowles J. (1986) Homology between cellulase genes of Trichoderma reesei: complete nucleotide sequence of the endoglucanase I gene. Gene 45: 253-263.

Rodrigues A., Passarini M.R., Ferro M. (2014) Fungal communities in the garden chamber soils of leaf cutting ants. J. Basic Microbiol. 54: 1186-1196.

Sadfi-Zouaoui N., Hannachi I., Rouaissi M. (2009) Biodiversity of Trichoderma strains in Tunisia. Canad. J. Microbiol. 55: 154-162.

Saloheimo M., Kuja-Panula J., Ylösmäki E., Ward M., Penttilä M. (2002) Enzymatic properties and intracellular localization of the novel Trichoderma reesei $\beta$-glucosidase BGLII (Cel1A). Appl. Environ. Microbiol. 68: 4546-4553.

Samuels G.J., Dodd S.L., Gams W., Castlebury L.A., Petrini O. (2002) Trichoderma species associated with the green mold epidemic of commercially grown Agaricus bisporus. Mycologia 94: 146-170.

Samuels G.J., Dodd S.L., Lu B.S., Petrini O., Schroers H.J., Druzhinina I.S. (2006) The Trichoderma koningii aggregate species. Studies Mycol. 56: 67-133.

Schoch C.L., Seifert K.A., Huhndorf S. (2012) Nuclear ribosomal internal transcribed spacer (ITS) region as a universal DNA barcode marker for fungi. Proc. Nat. Acad. Sci. 109: 6241-6246.

Schuster A., Bruno K.S., Collett J.R. (2012) A versatile toolkit for high throughput functional genomics with Trichoderma reesei. Biotech. Biofuels 5: 1 .
Seidl V. (2006) Molecular and physiological investigations of biocontrol by the genus Hypocrea/Trichoderma. Dissertation. Vienna University of Technology, Austria.

Singhania R.R., Patel A.K., Sukumaran R.K., Larroche C., Pandey A. (2013) Role and significance of beta-glucosidases in the hydrolysis of cellulose for bioethanol production. Bioresource Tech. 127: 500-507.

Sørensen A., Lübeck M., Lübeck P.S., Ahring B.K. (2013) Fungal beta-glucosidases: a bottleneck in industrial use of lignocellulosic materials. Biomolecules 3: 612-631.

Taylor J.W., Jacobson D.J., Kroken S. (2000) Phylogenetic species recognition and species concepts in fungi. Fungal Gen. Biol. 31: 21-32.

Tiwari P., Misra B., Sangwan N.S. (2013) $\beta$-Glucosidases from the fungus Trichoderma: an efficient cellulase machinery in biotechnological applications. BioMed Res. Inter. doi: $10.1155 / 2013 / 203735$

Topolovec-Pintarić S. (2019) Trichoderma: invisible partner for visible impact on agriculture. [in:] Trichoderma - the most widely used fungicide. IntechOpen.

White T.J., Bruns T., Lee S., Taylor J. (1990) Amplification and direct sequencing of fungal ribosomal RNA genes for phylogenetics. PCR protocols: a guide to methods and applications 18: 315-322.

Wood T.M. (1988) Preparation of crystalline, amorphous, and dyed cellulase substrates. Meth. Enzymol. 160: 19-25.

Wu G., He R., Jia W., Chao Y., Chen S. (2011) Strain improvement and process optimization of Trichderma reesei Rut C30 for enhanced cellulase production. Biofuels 2: 545-555.

Zhanga F., Bunterngsookc B., Lia J.X. (2019) Regulation and production of lignocellulolytic enzymes from Trichoderma reesei for biofuels production. Adv. Bioenergy 4: 79-119. 